
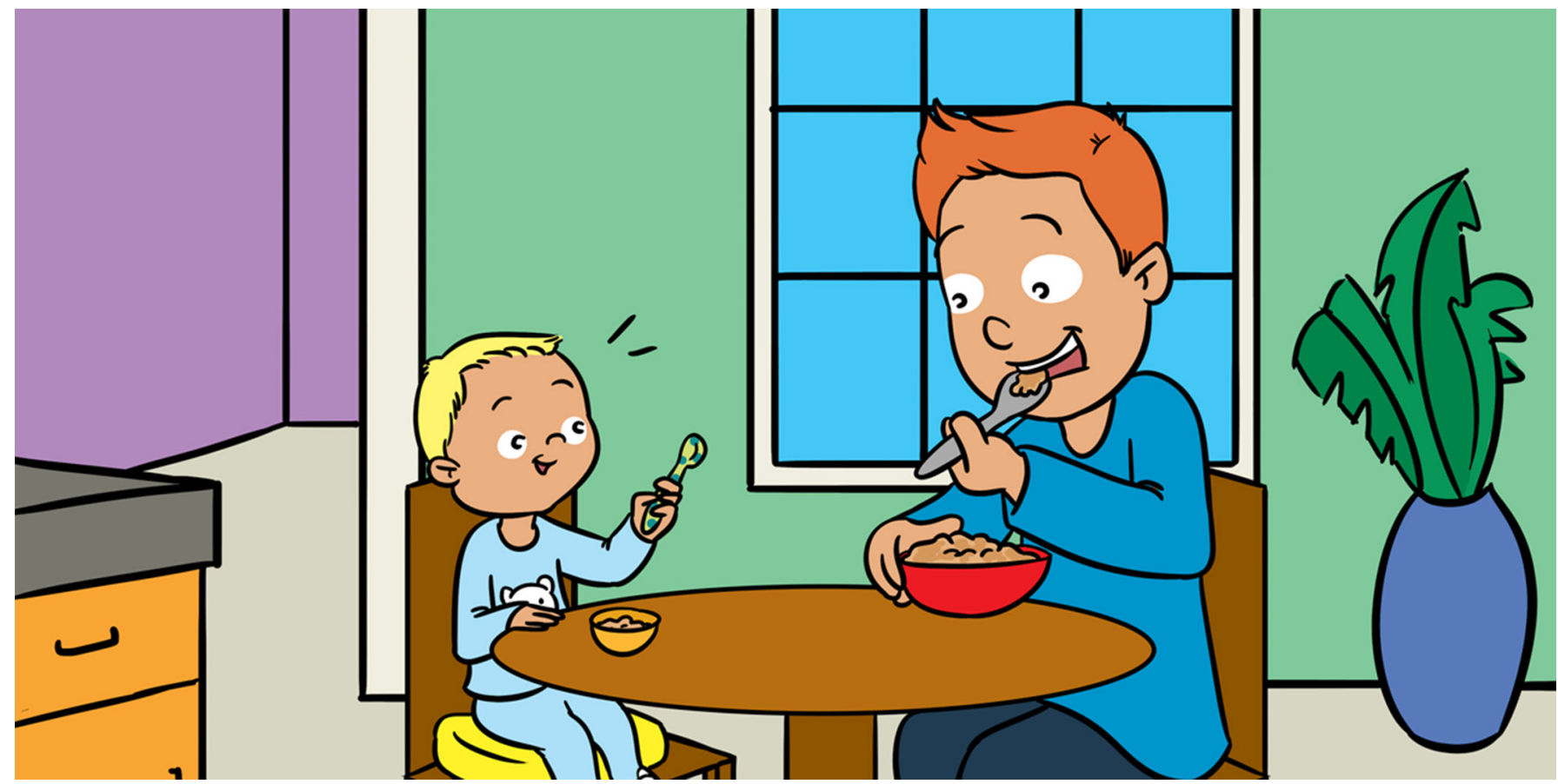

\title{
WHAT IS GOING ON IN BABIES" BRAINS WHEN THEY LEARN TO DO SOMETHING?
}

Kelsey L. Frewin ${ }^{1}$, Emma McEwen ${ }^{1}$, Sarah A. Gerson ${ }^{1 *}$, Harold Bekkering ${ }^{2}$ and Sabine Hunnius ${ }^{2}$

${ }^{1}$ Cardiff University Centre for Human Developmental Science, School of Psychology, Cardiff University, Cardiff, United Kingdom

2 Donders Institute for Brain, Cognition and Behaviour, Radboud University Nijmegen, Nijmegen, Netherlands

YOUNG REVIEWERS:

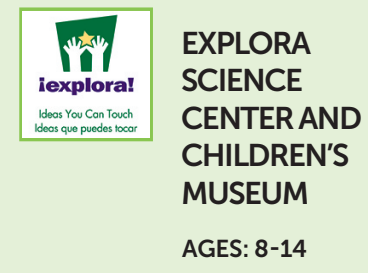

Actions are important. We need to know how to do all sorts of actions in our everyday lives, like using a fork to eat and using a pen to write. We have an easier time understanding the actions we see other people do if we have done the same actions before ourselves. It helps us understand why other people choose to use the same action. Adults know lots of different actions, but babies are still learning how to do many things. They are just learning how to move around and how to play with toys. Babies also understand more about actions they have done before than actions they have not done. Is there something happening in their brains that might help them understand the actions they have done? Do babies' brains respond differently when they see an action they know how to do compared with one they have never done? Let us find out. 


\section{INTRODUCTION}

As an adult, I might learn new actions by taking a dance class or trying out a sport I have never done before. Learning new actions is not unusual, but for most people, their day-to-day actions are not so different from what they have done in the past. On the other hand, babies are constantly learning new things. They are discovering new objects, learning to move in new ways, and playing with new toys. You probably do not remember, but when you were a baby, you started out able to move your hands and arms but did not have much control over how you reached for new toys and played with them. Within the first year of life, babies are learning how to do lots of things themselves, but they are also figuring out how and why other people do things.

Research has taught us that learning how to do things themselves helps babies understand more about why other people do those same actions [1]. This is interesting, because it means that learning new actions is important both for learning those new skills and for learning more about other people around us. We know that this is also true for adults. Some experiments have looked at brain activity in adult professional dancers who practice difficult dance moves but also watch dance partners move in ways they cannot. This research has shown that when the dancers watch other people perform dance moves, their brains react more to dance moves that they can do themselves, compared with the moves they cannot do $[2,3]$. It seems that being able to do a certain action changes how adult brains react when they see other people doing the same action. This made us wonder if babies' brains, which have much less experience with actions than adult brains, also react differently to actions the babies can do.

We wanted to find out if babies' brains also respond more to an action they already know how to do themselves compared to one they have only watched other people do. But before we go on to tell you how we conducted our study, we will explain how we measured the brain activity of babies.

\section{HOW CAN YOU MEASURE WHAT IS GOING ON IN A BABY'S BRAIN?}

To look at brain activity, we used a technique called electroencephalography (electro-en-ce-pha-lo-gra-phy), or EEG for short. EEG is used for measuring electrical activity in the brain. Your brain is made up of approximately 86 billion tiny brain cells called neurons. Neurons communicate with each other by sending small amounts of electricity to each other, and it is this communication that enables your brain 


\section{ELECTRODE}

Electrodes are special types of sensors that pick up electrical activity. They are normally made of metal.

\section{MU RHYTHM}

This is a type of signal in the brain. It changes when we do an action/ movement or when we see someone else do an action/movement.

\section{SENSORIMOTOR CORTEX}

This is the area of your brain that is responsible for actions and movements. It also processes information received about touch, body position and body movement.

\section{Figure 1}

(A) A picture of a baby wearing an EEG cap in one of our experiments. (B) Here is an image of a human brain. The area highlighted in blue is the sensorimotor cortex (Brain image was adapted from source https://www. macmillan.org.uk/ information-andsupport/braintumours/ understanding-cancer/ the-brain.html).

to perform all its functions. To pick up this electrical signal, we had babies wear a special cap with lots of wires on it (see Figure 1A). These wires are called electrodes and they can detect these tiny electrical signals in the brain, just by making contact with the baby's head. We were then able to see brain activity in the forms of waves on our computer screen.

\section{BRAIN ACTIVITY: THE MU RHYTHM}

One measure we can get from this electrical signal is a brain wave called the mu rhythm. The mu rhythm tells us about brain activity that is happening in the sensorimotor cortex (see Figure 1B), an area of the brain that controls actions and movements as well as handling information about touch, body position and body movement. The mu rhythm is measured using the sensors in the middle of the EEG cap, known as the central region, which is found on the top of your head. Why did we use the mu rhythm to measure brain activity in response to actions? One reason is because we can measure this type of brain activity in babies easily using EEG. Other methods of measuring brain activity require the study participant to lie very still in a machine for a long time, which is not practical for babies. The other reason we used the mu rhythm is that we already know that the mu rhythm responds most when people are either doing something or watching someone else do something. For example, we know that the mu rhythm is active when babies watch another person doing something like reaching for a toy [4]. Based on this knowledge, we can then test how different kinds of actions change this activity. In our study, we used these changes in the mu rhythm to measure if there was a greater change in babies' brain activity for actions they learned how to do themselves compared with actions they had only seen other people do.

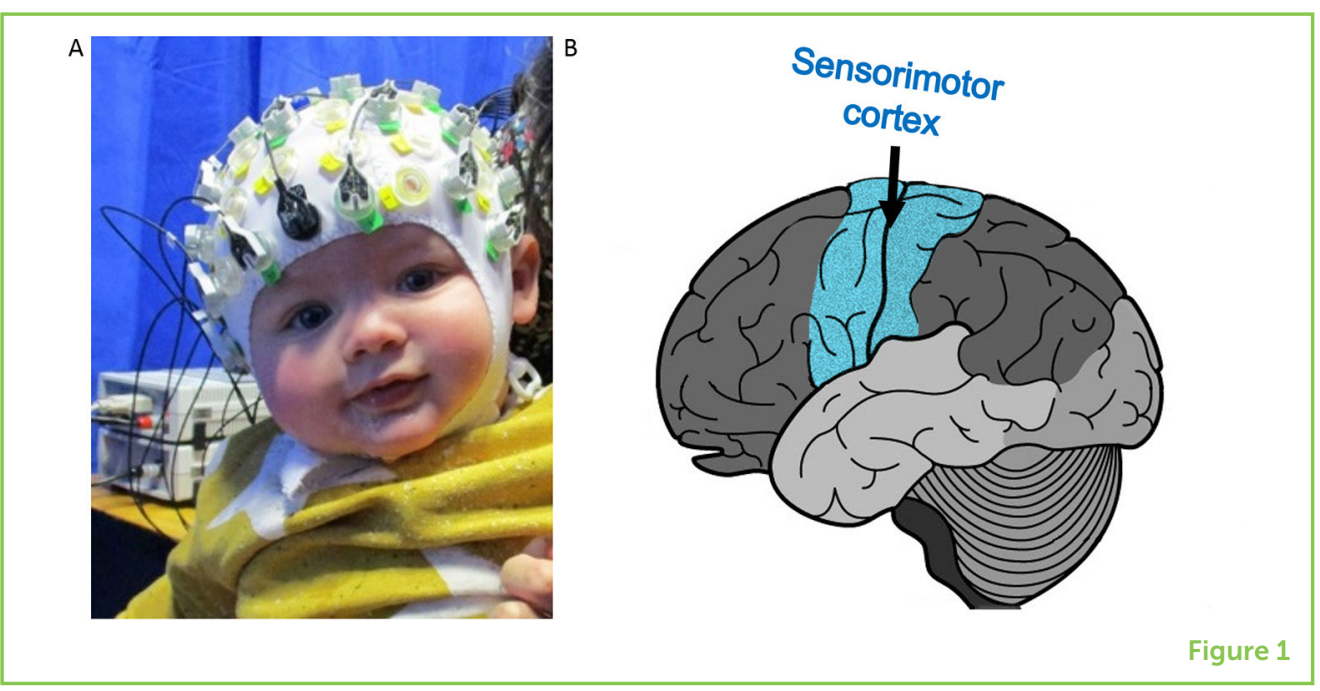




\section{LEARNING ACTIONS FOR OUR EXPERIMENT}

We had 17 babies learn two actions, using some fun toys that had unique sounds paired with the outcome of the actions being completed. One of the toys was a wooden puppet on top of a box, which spun around when the box was hit with a stick-like tool (see Figure 2A). The other was a box with a small hole in the top. A hook tool was used to pull a toy duck into the hole (see Figure 2B). The 10-months-old babies and their parents took both toys home for a week to play. When they were at home, the babies practiced playing with one of the toys and only watched their parent playing with the other toy. Each action was seen or practiced about three times over the week, for about 5 min each time. The toys we chose for our study were new to the babies and required actions they had not previously learned how to do. We chose these unique toys because we needed to study actions that 10-months-old babies would not yet know how to do physically but could learn in a short period of time.

After a week of playing with the toys, babies and their parents came into our lab to take part in our EEG experiment. When babies came back to the lab, they sat on their parents' lap, wearing an EEG cap so we could measure their brain responses, while they paid attention to the

ACTION OUTCOMES

Action outcomes are the consequences of an action being completed. In this experiment, a unique sound was made whenever one of the actions on the toys was completed, creating a link between the action and the sound.

\section{Figure 2}

(A) A baby learning one of our new actions at home. When the baby hits the toy with the stick the puppet spins. (B) A baby watching her mum perform one of our new actions at home. She pulls the duck into the hole with a hook. action outcomes. We made sure babies were sitting still, so we could be sure that mu rhythm activity was not related to the baby's movements but was the result of attending to the actions.

\section{PERFORMING ACTIONS CHANGES THE MU RHYTHM}

We already knew from other studies that the mu rhythm is activated when babies watch others perform actions [4]. In our study, we wondered if there would be a greater change in babies' mu rhythm activity for an action they had done themselves compared with an action they had only seen being done before. We expected that there would
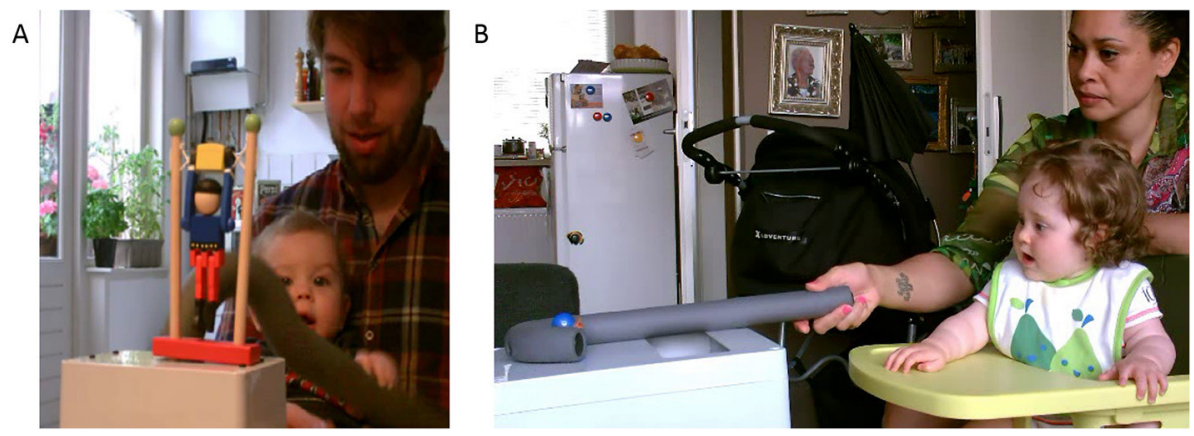

Figure 2 
Figure 3

In this graph, you can see that brain activity changed the most for the action babies had done before (the red bar) compared with the action that they had only seen before (the blue bar).

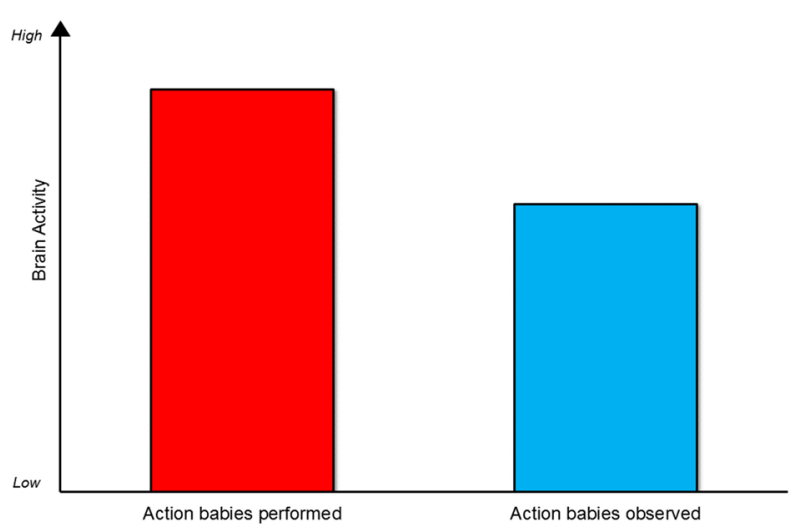

Figure 3

be a greater change in mu rhythm activity for the action the babies practiced doing themselves. But why did we expect this? As we already mentioned, we knew from previous research that adults show greater changes in brain activity when they see actions that they have tried doing themselves compared to actions they have only seen other people do [2]. We thought that we might find the same pattern in babies. We also knew from other studies that babies understand more about why we use an action once they are able to do it themselves, which we thought might have something to do with changes in the sensorimotor cortex [5].

So, what did we find? Just like in adults, the action that the babies had done themselves resulted in a greater change in brain activity than the action they only had seen their parent do. We even found that babies who were better at doing the action were even more likely to show this change in brain activity. As you can see in Figure 3, the red bar shows that brain activity in the sensorimotor cortex, which we measured using the mu rhythm, changed the most for the action babies learned themselves. We only detected this effect from the sensors in the central region of the EEG cap that we mentioned earlier, and not in other regions. This supports our prediction that there would be a greater change in brain activity for the action the babies did themselves, compared with the action they only watched their parent do. So, we can see that, in babies, the mu rhythm can be changed by learning to perform, rather than just by watching, new actions.

\section{WHAT DOES THIS ALL MEAN AND WHY IS IT IMPORTANT?}

Our study found that the brain activity that occurs while watching an action is greatly changed if the baby had performed the action in the previous week, but not if the baby had only observed his or her parent performing the action in the previous week. In other words, the sensorimotor cortex, the part of the brain that responds to actions, responded more to the action that babies had previously done themselves. This suggests that 
there is something special about actively practicing how to do an action, rather than just passively observing that action being done.

Before this study, we did not know whether babies' brains would show us that doing actions was important for understanding those actions. Now we know that, for babies, having active experience with an action is crucial for activating the sensorimotor cortex. So why is this important? Understanding how the brain learns about actions could help us better understand the ways that babies and children learn best. Our findings suggest that it might be helpful for parents to let their babies try out new actions for themselves, rather than just showing them actions, because the babies will learn more by doing an action themselves. When the babies later see another person performing that action, they are more likely to understand why that person might want to use that action. This sort of understanding helps us know more about the people around us. This is similar to how, at school, you are probably told to "actively engage" with learning, rather than passively observe-because active engagement helps you to learn better. For example, imagine you wanted to learn how to score a goal in soccer (football). While you can learn a bit about the technique from watching professional soccer players scoring on TV, you will probably best learn how to do this by practicing scoring goals on the soccer pitch yourself. If you learn by doing, then in the future, you will probably have a better understanding of why professional soccer players kick the ball in particular ways when trying to score a goal.

Even though this study showed that babies' brains respond more to actions they have practiced themselves, we have still got lots more research to do to help us understand how this impacts babies' learning and development. Want to know more? Get involved in science and help us answer more questions about babies' brains!

\section{ORIGINAL SOURCE ARTICLE}

Gerson, S. A., Bekkering, H., and Hunnius, S. 2015. Short-term motor training, but not observational training, alters neurocognitive mechanisms of action processing in infancy. J. Cogn. Neurosci. 27:1207-14. doi: 10.1162/jocn_a_00774

\section{REFERENCES}

1. Gerson, S. A., and Woodward, A. L. 2014. Learning from their own actions: the unique effect of producing actions on infants' action understanding. Child Dev. 85:264-77. doi: 10.1111/cdev.12115 
2. Calvo-Merino, B., Grèzes, J., Glaser, D. E., Passingham, R. E., and Haggard, P. 2006. Seeing or doing? Influence of visual and motor familiarity in action observation. Curr. Biol. 16:1905-10. doi: 10.1016/j.cub.2006.07.065

3. Cross, E. S., Hamilton, A. F., and Grafton, S. T. 2006. Building a motor simulation de novo: observation of dance by dancers. Neuroimage 31:1257-67. doi: 10.1016/j.neuroimage.2006.01.033

4. Marshall, P. J., Young, T., and Meltzoff, A. N. 2010. Neural correlates of action observation and execution in 14-month-old infants: an event-related EEG desynchronization study. Dev. Sci. 14:474-80. doi: 10.1111/j.1467-7687.2010.00991.x

5. Hunnius, S., and Bekkering, H. 2014. What are you doing? How active and observational experience shape infants' action understanding. Philos. Trans. $R$. Soc. Lond. B Biol. Sci. 369:20130490. doi: 10.1098/rstb.2013.0490

SUBMITTED: 06 September 2018; ACCEPTED: 25 February 2019; PUBLISHED ONLINE: 15 March 2019

EDITED BY: Kathleen Y. Haaland, University of New Mexico, United States

CITATION: Frewin KL, McEwen E, Gerson SA, Bekkering H and Hunnius S (2019) What is Going on in Babies' Brains When They Learn to do Something? Front. Young Minds 7:44. doi: 10.3389/frym.2019.00044

CONFLICT OF INTEREST STATEMENT: The authors declare that the research was conducted in the absence of any commercial or financial relationships that could be construed as a potential conflict of interest.

COPYRIGHT @ 2019 Frewin, McEwen, Gerson, Bekkering and Hunnius. This is an open-access article distributed under the terms of the Creative Commons Attribution License (CC BY). The use, distribution or reproduction in other forums is permitted, provided the original author(s) and the copyright owner(s) are credited and that the original publication in this journal is cited, in accordance with accepted academic practice. No use, distribution or reproduction is permitted which does not comply with these terms.

\section{YOUNG REVIEWERS}

\section{EXPLORA SCIENCE CENTER AND CHILDREN'S MUSEUM, AGES: 8-14}

The Explora Young Minds reviewers are a group of science enthusiasts working with museum educators and mentors from the University of New Mexico. We enjoy learning about the brain through the articles. We also enjoy asking questions and making suggestions to help the scientists make their work more understandable for everyone! We were helped by our Science Mentor, Crina Floruta, who is a M.D./Ph.D. candidate working in a neuroscience lab and who is hoping to pursue a Neurosurgical residency in the future. She loves Albuquerque, hiking, reading, and talking about the brain with people. 


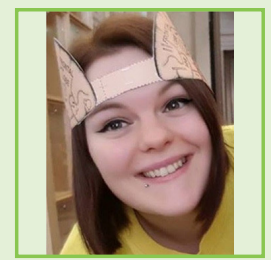

\section{AUTHORS}

\section{KELSEY L. FREWIN}

I am a Research Assistant in Wales, UK. I help run studies that explore how babies and young children develop. In particular, I am really interested in understanding how your experiences as a baby are related to skills you develop when you are older, like learning words. I have always been interested in psychology and understanding how our brains become so impressive, so I think I have an awesome job! When I am not thinking about babies' brains, you can find me watching sci-fi shows and reading my favorite fiction books!

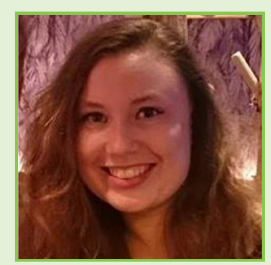

\section{EMMA MCEWEN}

I am a final year undergraduate Psychology student interested in Comparative Psychology. This involves giving tasks to different species, such as chimpanzees and children, and seeing how they perform. In my spare time, I enjoy cooking with friends, cross-stitch, and going on walks in the countryside.
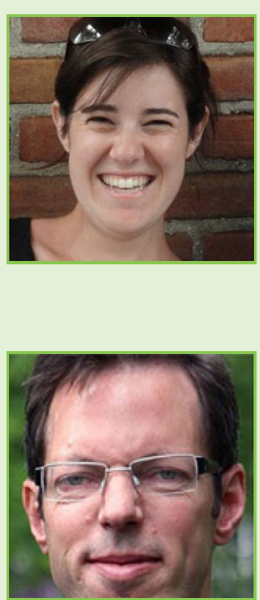

\section{HAROLD BEKKERING}

I am a Professor in Psychology, and in my research, I want to find out how our brains make sense of and predict the world around us. In my free time, I enjoy playing chess. I also love squash, soccer, and like many Dutch people cycling.

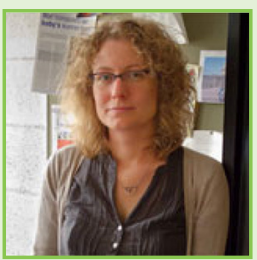

\section{SABINE HUNNIUS}

I am interested in how children, and especially babies, develop. I always found it amazing how quickly babies learn and change into toddlers who can move around and talk. Is not it crazy that nobody can remember what it was like being a baby, although we have all been a baby once? This is why I study how babies and children perceive the world and how they start to make sense of the things they experience as they grow older. 